\title{
ПРАВОВЫЕ ПРОБЛЕМЫ РАЗВИТИЯ ИНСТИТУТОВ ИНФРАСТРУКТУРЫ СТРАХОВАНИЯ КРЕДИТНЫХ РИСКОВ В УКРАИНЕ
}

Развитие кредитной сферы сопровождается формированием системы институтов, которые предназначены обеспечивать её эффективное и безопасное функционирование. Кредитной деятельности, независимо от общественно-экономической формации, всегда был присущий рисковый характер. Вероятность реализации тех или иных кредитних рисков определяются следующими факторами: уровнем развития кредитного и страхового рынков; уровнями развития кредитной и культуры; использованием компьютерных технологий в кредитной сфере; способом соединения и развитием факторов кредитной деятельности (человеческого, технического, организационного, информационного); общественным разделением труда, усилением тенденций глобализации и неравномерности развития кредитных учреждений и страховых организаций, в основе которой лежат различия не только в процедурах осуществления операций, но и вопросы специализации. ${ }^{1}$ Институциональные условия на определенном этапе выхода из кризиса способствуют внедрению тех инноваций, которые не были реализованы в условиях спада деловой активности и которые влекут за собой новые идеи, возникшие до и в момент депрессии. ${ }^{2}$ Так, в предкризисный период в Украине получили развитие определенные виды кредита, которые пользуются спросом и сегодня. Однако кризис выявил проблемы и риски в механизмах кредитования и страхования рисков кредитной сферы. Развитие кредитного страхования способствует осуществлению двойного контроля за рисками кредитной сферы.

Исследованию отдельных институтов инфраструктуры кредитного страхования посвящены труды многих ученых, однако их особенностям и роли в обслуживании кредитного страхования уделено недостаточно внимания.

\footnotetext{
1 Пронская Н. Концептуальные положения управления банковскими рисками//Ресурсы, информация снабжение, конкуренция. - 2010. - №3. - С. 83

2 Сухарев О.С. Институциональная экономика: теория и политика.- М.: Наука, 2008. - С. 202
} 
Кризис способствовал росту качества институтов кредитного страхования. Формированию надлежащей инфраструктуры кредитного страхования в Украине способствуют существенные институциональные изменения. Субъектами инфраструктуры кредитного страхования выступают бюро кредитных историй, коллекторские фирмы, ипотечные центры, финансовые консультанты, оценщики имущества, нотариусы, агентства недвижимости (риэлторы), автосалоны, торговые организации. Ошибки или сбои в работе инфраструктуры могут существенно затронуть интересы основных субъектов кредита и нанести им ущерб. Реализации кредитных страховых продуктов в Украине будет способствовать развитие ипотечных центров, главной целью которых является комплексное обслуживание клиента, желающего получить кредит на приобретение недвижимости или осуществлить другие операции с недвижимостью. Клиент может получить консультации и помощь всех необходимых специалистов по предоставлению кредитов, нотариальному оформлению, поиску и подбору недвижимости, оценке недвижимости, страхованию ипотечных рисков. Особенностью ипотечных центров является то, что каждая программа кредитования строится исходя из особенностей заемщика. Подтверждением преимуществ ипотечных центров является то, что они способствуют значительному приросту ипотечных портфелей банков. Однако, функционирования ипотечных центров имеет и ряд недостатков. Среди них можно выделить специализацию центров на продвижении только ипотечных продуктов, что не дает возможности получения клиентом информации по другим банковским продуктам, продолжительность процесса оформления кредита.

Альтернативой ипотечным центрам могут стать финансовые консультанты, которые в пределах одного офиса предлагают клиенту целый ряд ипотечных программ различных банков и ипотечных страховых продуктов. Кроме того, финансовые консультанты осуществляют переговоры с банком, помогают собрать необходимые документы, следят за законностью кредитного соглашения, ускоряют процедуру принятия кредитного решения, а также способствуют принятию кредитной комиссией положительного решения. Учитывая высокие цены на недвижимость, актуальными для украинсского рынка кредитного страхования остаются проблемы жилищного ипотечного кредитования. Это во многом определяет важность деятельности риэлторов как субъекта инфраструктуры рынка кредитного страхования. Негативное влияние на рынок недвижимости, а следовательно и на кредитное страхование в Украине имеет отсутствие закона о риэлторской деятельности, хотя в стране функционируют Ассоциация специалистов по вопросам недвижимости и Риэлторская палата Украины. Достаточно вспомнить о том, что последний мировой экономический кризис начался на рынке недвижимости. В развитых странах уделяется значительное внимание регулированию этого сегмента инфраструктуры 
рынка кредитного страхования. Например в США, где недвижимость составляет 50\% национального богатства страны, значение риэлторов подчеркивается обязательными встречами президента страны и президента Национальной ассоциации риелторов дважды в год. ${ }^{3}$ Таким образом, назначение создании и утверждении закона, регулирующего деятельность риэлторов в Украину, будет заключаться в сведении к минимуму случаев мошенничества на рынке недвижимости. Упорядочение нормативно-правовой базы регулирования риэлторской деятельности будет способствовать уменьшению ипотечных рисков и, как следствие, уменьшению страховых выплат.Еще одним институтом кредитного страхования выступает бюро кредитных историй, содержащий информацию о выполнении физическим лицом обязательств по кредитным договорам. Прообразом кредитного бюро стало создание в 30-х годах 19 века базы данных Льюис Тэппен с Манхеттена. Агентство Тэппена позже стало известно как RG / Dun \& Co (c 1933 года - Dun \& Bradstreet). Согласно Закону Украины «Об организации формирования и обращения кредитных историй» от 23.06.2005 года № 2704 бюро кредитных историй является юридическим лицом, исключительной деятельностью которого является сбор, хранение, использование информации, которая составляет кредитную историю. В Украине создано более 10 млн кредитных историй. ${ }^{4}$ В западных странах в бюро кредитных историй есть информация о 90\% граждан страны. ${ }^{5}$ Функционирование бюро кредитных историй является полезным как кредитным учреждениям, поскольку помогает минимизировать риски, так и заемщикам, поскольку позволяет быстро и на более выгодных условиях получить кредит. Ведь процентная ставка по кредиту учитывает также затраты на риск и на получение и проверку информации, необходимой для предоставления кредита. Понятно, что услуги бюро кредитных историй являются полезными и для страховых компаний, учитывая перспективность развития ипотечного рынка. Это даст дополнительную возможность выявления мошенников и минимизирует кредитные риски, поскольку собственные базы информации страховых компаний является ограниченными по сравнению с бюро кредитных историй. Хотя существуют мнения среди специалистов по созданию аналогичных бюро среди страховщиков ${ }^{6}$, на наш взгляд, это неуместно в связи с тем, что подобный институт уже существует на финансовом рынке Украины.

Кредитный бум и дальнейший кризис повлекли за собой рост проблемных кредитов, что активизировало появление и развитие коллекторских компаний.

3 Почему закон о риелторской деятельности трижды не приняли? [Электронный ресурс]. - Режим доступа: http://www.unia.com.ua/ukr/?nid=mnews|5975

4 Десять мільйонів осіб в Україні отримали кредит протягом останніх двох років. - [ Електронний ресурс].Режим доступу: http://www.zik.com.ua/ua/news/2009/01/15/165453

5 Там же

6 Загребной В. Н. Наше дело обречено на успех. Летопись страхового бизнеса. - К.: Украинское агентство финансового развития, 2010.- С. 388 
Это является традиционным этапом после активного развития банковского кредитования. Основной задачей коллекторских компаний является профессиональное взыскание проблемных задолженностей. Их преимуществами являются:

- наличие отработанных технологий, которые позволяют в течение короткого периода времени охватить большое количество должников;

- наличие значительного числа сотрудников, специализирующихся на обслуживании долгов;

- минимизация затрат, поскольку содержать собственные службы взыскания долгов является делом затратным, что в свою очередь связано с ростом тарифов и цен для добросовестных плательщиков;

- возможность возвращения определенной части задолженности. Благодаря коллекторским агентствам банки и страховые компании возвращают от 10 до $75 \%$ сомнительных долгов. ${ }^{7}$

Коллекторский бизнес развивается достаточно бурно. Он возник в 60-х годах прошлого века в США, а уже в начале 80-х годов получил распространение в Европе. В США существует более 8000 коллекторских компаний, в странах ЕС - более 10000 (в частности, в Польше - более 700), в России - 250. ${ }^{8}$ Сначала коллекторские агентства создавались как дочерние организации банков и обслуживали исключительно их долги. В России коллекторские агентства начали появляться в 2004 году. Первое коллекторское агентство в России ЗАО «ФАСП» - было зарегистрировано 9 августа 2004 года.

На Украине первая коллекторская компания «Credit Collection Group» возникла осенью 2006 года. На начало 2008 года их количество уже составило 15,9 а сейчас $-50^{10}$. По прогнозам специалистов в Украине количество коллекторских компаний в перспективе должно вырасти до тысячи. ${ }^{11}$

На Украине с коллекторскими компаниями сотрудничают 60-70 банков. В начале кризиса портфели банковских кредитов физических лиц составляли $80 \%$, страховых компаний - 6\%, телекоммуникационных компаний - 1\% об-

7 Коллекторский бизнес в Украине: who is who? .- [Электронный ресурс].- Режим доступа:http://roadnews. wordpress.com/2011/10/26/коллекторский-бизнес-в-украине-who-is-who/

8 Аппетиты охотников за долгами растут.- [Электронный ресурс].- Режим доступа: http://www.kontrakt.ua/ua/ readarticles/n116.html

9 Волховский И. Задачи коллекторской компании - наладить такие взаимоотношения с банком, чтобы будучи клиентом, он остался им навсегда// Зеркало недели.-№8(867)1-7 марта 2008.- Электронный ресурс.Режим доступа:http://www.dt.ua/2000/2675/62189/

10 Политический обозреватель.- [Электронный ресурс].- Режим доступа: http://www.politic.com.ua/ukraine/ economics/892

11 Волховский И. Задачи коллекторской компании - наладить такие взаимоотношения с банком, чтобы будучи клиентом, он остался им навсегда// Зеркало недели.-№8(867)1-7 марта 2008.- [Электронный ресурс].Режим доступа:http://www.dt.ua/2000/2675/62189/ 
щего портфеля украинских коллекторов. Однако, уже в 2009 году портфель страховых компаний составил по разным оценкам 20-40\%. Желание страховщиков покрыть полученные за время кризиса убытки побудило их активнее обращаться за помощью к коллекторам. По прогнозам коллекторской компании «Европейское агентство по возврату долгов» в 2012 году на Украине портфели банков будут составлять $68 \%$, а портфели страховых компаний - $13 \%{ }^{12}$

По данным коллекторов первое место в рейтинге рискованности занимают потребительские кредиты, а затем - автомобильные и ипотечные кредиты. В кредитном страховании страховые компании зачастую обращаются к услугам коллекторских компаний за помощью по регрессным требованиям по возмещениям, которые были оплачены по договорам КАСКО и по договорам страхования кредитов (от риска непогашения).

В первую очередь коллекторские услуги являются привлекательными для страховых компаний, осуществляющих страхование автомобилей по программам КАСКО. С каждым годом количество застрахованных автомобилей увеличивается и, разумеется, растет количество страховых случаев. По некоторым оценкам, в Европе осуществляется реализация в кредит почти 70\% автомобилей. ${ }^{13} \mathrm{~B}$ докризисный период на Украине количество реализованных в кредит автомобилей составляло по отдельным сегментам до 80\%. Однако, уже в 2010 году, по разным оценкам, с помощью кредитных программ было реализовано лишь 15-18\% автомобилей. При этом, по данным банков, в 2010 году до 80\% автокредитов предоставлялось при активном участии автосалонов. По мнению специалистов, автомобильный рынок будет расти ежегодно на 15-20\% и достигнет объемов 2008 года не ранее 2015 года. ${ }^{14}$ Это повлияет и на рост продаж полисов КАСКО. Но, если в Европе их имеют около 90\% водителей, то наУкраине этот показатель в десять раз меньше. ${ }^{15}$ Страховщики имеют право выставлять регрессные требования к лицам, виновным в наступлении страхового случая и нанесении ущерба их клиентам. После оплаты ремонта автомобиля по полису КАСКО страховой компанией, она может потребовать компенсацию расходов у виновника ДТП. В ряде случаев страховые компании могут предъявлять регрессные требования и к своим клиентам, которые приобрели у них полис страхования гражданской ответственности владельцев автотранспорта. По оценкам страховщиков, общая сумма регрессных требований к водителям, которые они готовы передать коллекторам, составляет около 300-500 млн грн.

\footnotetext{
12 Фомина К. Перспективы развития коллекторского бизнеса.- [Электронный ресурс].- Режим доступа: http:// www.legalweekly.com.ua/article/?uid=611

13 Банки и страховые компании: кросс-продажи// Банковское обозрение.-2005.-№12.-32-33 с.

14 Матусяк С. Одинаково разные// Автоцентр.-2011.-№6.- С. 29

15 Шляховой В. Подводные камни украинского страхования// Автомир.-2011.-№29.- С. 6
} 
Коллекторы оценивают ее примерно на около 1 млрд грн. При этом в работе у них находится не более 5-7\% данной суммы.

Эффективность работы с портфелями регрессов, которые им передаются на обслуживание, варьируется в пределах 10-40\%. Коллекторы обещают её довести до 60-70\%. Успешность тандема страховщиков и коллекторов во многом зависит от размера дисконта из портфеля долгов, который большинство страховых компаний считают завышенным. Страховые компании готовы к сотрудничеству с коллекторами при условии получения 30-50\% долга, что не удовлетворяет коллекторов, которые объясняют свое нежелание сотрудничества сложностями работы со страховщиками. Для банков условия сотрудничества с коллекторскими агентствами являются более благоприятными, поскольку сумма вознаграждения колеблется в пределах 10-50\%, хотя стандартом является сумма от 15 до $35 \% .^{16}$

Различиями в работе коллекторов с должниками страховщиков и банков заключается в том, что:

- при обслуживании банка для коллектора главное - найти должника, а при работе со страховщиками - доказать его вину. Как правило, виновники аварий даже не догадываются о своих долгах перед страховыми компаниями. Кроме того, при заполнении актов сотрудниками Государственной автомобильной инспекции существует риск предоставлении ложных сведений. В этом случае наблюдается наличие психологических аспектов в работе с должниками, которые просто не понимают, почему они должны платить;

- наблюдается значительная продолжительность во времени процедуры взыскания долгов, поскольку необходимо пройти определенные юридические процедуры. Документальное закрепление правоотношений банка с должниками находится на высоком уровне. Лишь около 5\% должников банков категорически отказываются от своих долгов. В то время как $80 \%$ проблемных долгов страховых компаний возвращаются по решению судов, и всего лишь $10 \%$ долгов - банкам;

- у большинства страховщиков отсутствуют качественные базы данных о своих должников. Поскольку страховые компании не имеют электронного реестра своих должников, то не могут предоставить коллекторам достоверную информацию о них; 
- в большинстве страховых компаний процесс сотрудничества с коллекторами и должниками не структуризирован в целом.

В условиях кризиса увеличивается количество коллекторов. Кроме того, наблюдается уменьшение результативности их деятельности. Если в докризисное время коллекторам удавалось взыскивать в среднем до 50-70\% долгов, которые им передавались, то во время кризиса - 10-25\% ${ }^{17}$, поскольку платежеспособность населения в этот период значительно уменьшились. Кризис приносит увеличение количества клиентов коллекторских компаний. До кризиса с коллекторскими агентствами сотрудничало около 25 банков, а в период кризиса - более 40. В условиях кризиса наблюдается «тенизация» коллекторской деятельности, что, по оценкам Ассоциации коллекторского бизнеса Украины, составляет до 50\% рынка. Кроме того, наблюдается значительная концентрация рынка. Около 80-90\% официального рынка коллекторских услуг в Украине контролируется крупными компаниями (CCG, Служба исполнения обязательств, Европейское агентство по возврату долгов, Verdict, «Укрборг», Украинская коллекторская группа). Большинство клиентов предпочитают обращаться именно к ним, поскольку, в отличие от мелких коллекторских агентств, достаточный объём ресурсов позволяет им действовать в рамках этики и закона.

Развитие коллекторских компаний на Украине сдерживают отсутствие совместной работы коллекторов по развитию технологий и стандартов качества, отсутствие кодекса этики коллекторов; гармонизации взаимодействия с государственными органами; отсутствие единого закона, который регулировал бы деятельность коллекторских компаний.

К перспективам развития коллекторской деятельности следует отнести:

- активизацию работы с долгами по кредитным картам и займам в сегменте малого и среднего бизнеса;

- сокращение объемов деятельности украинских коллекторов вследствие значительного сокращения потребительского кредитования в течение длительного периода и сокращение новых просрочек кредитов. Существует мнение, что коллекторские компании будут либо закрываться либо перепрофилироваться в финансовые компании или юридические фирмы;

- ужесточение правовых условий функционирования коллекторов, поскольку с 1.01.2012 года вступил в силу закон «О внесении изменений в некоторые законодательные акты Украины относительно усиления от-

17 Как сегодня работают коллекторские компании? .- [Электронный ресурс].- Режим доступа: http://odindetective.uaprom.net/a24916-kak-segodnya-rabotayut.html 
ветственности за нарушение законодательства о защите персональных данных». Этот документ предусматривает уголовную ответственность за нарушения в области защиты персональной информации, если это приводит к распространению или искажению этой информации и наносит лицу ущерб, а также за предоставление несанкционированного доступа к персональной информации и за ее передачу третьим лицам. За данные нарушения можно «получить» до пяти лет лишения свободы. Эта ситуация возникла вследствие принятия Закона «О защите персональных данных».

Главной проблемой коллекторских компаний на Украине является отсутствие законодательства, которое бы четко регулировало их деятельность. Это привело к возникновению так называемых антиколлекторов. Если обратиться к зарубежному опыту то, например, в США в 1978 году был принят закон «О добросовестной практике изъятия задолженностей», который определяет, что угрозы в отношении имущества физического лица-должника, его близких, его репутации, употребление оскорбительных и неприличных выражений при разговоре, являются неправомерными действиями, за которые коллекторские компании несут ответственность.

Таким образом, становлению и развитию рынка страхования кредитных рисков должно способствовать эффективное функционирование институтов, входящие в его инфраструктуру - бюро кредитных историй, ипотечных центров, финансовых консультантов, коллекторских компаний. При этом государству необходимо создатьнормативно-правовое обеспечение на уровне, который соответствует успешкой зарубежней практике.

\section{БИБЛИОГРАФИЯ}

1. Банки и страховые компании: кросс-продажи// Банковское обозрение.-2005.-№12.

2. Матусяк С. Одинаково разные// Автоцентр.-2011.-№6.

3. Пронская Н. Концептуальные положения управления банковскими рисками//Ресурсы, информация снабжение, конкуренция. - 2010. - №3.

4. Сухарев О.С. Институциональная экономика: теория и политика.- М.: Наука, 2008.

5. Шляховой В. Подводные камни украинского страхования// Автомир.-2011.-№29.

6. Волховский И. Задачи коллекторской компании - наладить такие взаимоотношенияс банком, чтобыбудучи клиентом, он остался им навсегда// Зеркало недели.-№8(867)1-7 марта 2008.

7. Загребной В.Н. Наше дело обречено на успех. Летопись страхового бизнеса. - К.: Украинское агентство финансового развития, 2010. 
Правовые проблемы развития институтов инфраструктуры страхования кредитных...

\section{LEGAL PROBLEMS WITH THE DEVELOPMENT OF INSTITUTES AND INFRASTRUCTURE FOR THE INSURANCE OF CREDIT RISKS IN UKRAINE}

The article explores the nature of the infrastructure and institutions at credit risk insurance. The text concentrates on a few aspects of the problem, but the main topic refers to the economic crisis and its influence on credit risk. It is emphasized that the government is aware of the problem and passed a law to prevent this problem. Moreover, the text justifies the advantages and development trends of credit risk insurance.

Key words: insurance of credit risks, institute of credit insurance, collection business 